IV Congreso Internacional Estética y Política Poéticas del desacuerdo para una democracia plural 16 y 17 de octubre. Valencia

Doi: http://dx.doi.org/10.4995/CEP4.2019.10492

\title{
Afectos transfílmicos: hacer y sentir en torno a la proyección audiovisual
}

\author{
Aurelio Castro-Varela
}

Facultat de Belles Arts, Universitat de Barcelona, aurelio.castro@ub.edu

\begin{abstract}
In my doctoral research, titled Aesthetics of the audiovisual screening. Assembly, fiction and right to the city in Poble Sec, Barcelona, I explored the aesthetic and pedagogical practice of two collectives arosed from the 15M Movement: the Occupy Poble Sec Cinema Forum and the Fiction Workshop. Both of them used the screening of images as the main method in their activies, employing in addition a fluid mobile apparatus to move across several points of a same neighbourhood. Member and co-founder of the two groups, the ethnographic tracking I carried out of their corresponding trajectories, from 2012 to 2014 , sought to clarify the assemblage of human and non-human entitities that supported their mode of existence in common and the socio-material politics which shaped it.

However, at the end of the dissertation writing I started to realize that the role of affects had been crucial during the development and maintenance of those assemblages, while my research had also disregarded that issue. This paper aims to restore tentatively this lack through authors such as Anna Hickey-Moody (2019) or Elizabeth de Freitas (2018). In particular, De Freitas defines "transindividual sympathy" as "the process of becoming other that does not erase the other" (p. 6). But how could it be recognized in ethnographic and political terms? What are its traces and evidences, its intensities and modes of appearance, its openings and limits?
\end{abstract}

Keywords: affects, audiovisual screening, assemblage, ethnography, transindividual sympathy, politics, aesthetics, 15M Movement

\begin{abstract}
Resumen
En mi investigación doctoral, titulada Estética de la proyección audiovisual. Asamblea, ficción y derecho a la ciudad en Poble Sec, Barcelona, exploré la práctica estética y pedagógica de dos colectivos surgidos en torno al Movimiento 15M: el Cinefòrum de la Assemblea de Vë̈ns i Veïnes de Poble Sec y el Taller de Ficció. Ambos empleaban la proyección de imágenes como herramienta principal en sus actividades, y lo hacían además mediante un dispositivo fluido y móvil, el cual les permitía circular por diversos puntos de un mismo barrio. Miembro y cofundador de los dos, el seguimiento etnográfico que llevé a cabo de sus respectivos devenires, entre 2012 y 2014, trató de esclarecer el ensamblaje de elementos humanos y nohumanos que sostenía su modo de existencia en común y la política sociomaterial que le daba forma.
\end{abstract}

Sin embargo, al término de la escritura de la tesis empecé a valorar que el papel de los afectos había sido crucial en la constitución y mantenimiento de tales ensamblajes, a la vez que desatendido por mi investigación. Esta comunicación es una primera tentativa de restituir esa falta a partir de autoras como Anna Hickey-Moody (2019) o Elizabeth de Freitas (2018). Concretamente, esta última define "transindividual sympathy" como "el proceso por el que se deviene otro sin borrar al otro" (p. 6). Ahora bien, ¿cómo se puede reconocer ese proceso en términos etnográficos y políticos? ¿Cuáles son sus rastros y sus evidencias, sus intensidades y sus modos de aparecer, sus aperturas y sus límites?

Palabras clave: afectos, proyección audiovisual, ensamblaje, etnografía, transindividual sympathy, política, estética, Movimiento $15 \mathrm{M}$ 


\section{Introducción}

A concept is a brick. It can be used to build the courthouse of reason. Or it can be thrown through the window.

(Massumi, 1987, p. xii)

La escritura de una tesis doctoral no se presta dócilmente a la obligación académica de un cierre. En mi propia experiencia, una línea de virtualidades asedió el paso hacia el punto y final y lo ensanchó con nuevos requerimientos. Mientras empezaba unas conclusiones que no lo eran, puesto que la andadura de uno de los casos de estudio -el Solar de la Puritodavía proseguía, y yo continuaba también plenamente inmiscuido en ella, una cita de Gilles Deleuze y Félix Guattari (1987) vino a iluminar de repente una región de la investigación que había permanecido hasta entonces relativamente ensombrecida. La cita pertenecía a la versión en inglés de Mille Plateaux, es decir, a A Thousand Plateaus:

Assemblages are passional, they are compositions of desire. Desire has nothing to do with a natural or spontaneous determination; there is no desire but assembling, assembled, desire. The rationality, the efficiency, of an assemblage does not exist without the passions the assemblage brings into play, without the desires that constitute it as much as it constitutes them. (p. 399)

Mi investigación doctoral, titulada finalmente Estética de la proyección audiovisual. Asamblea, ficción y derecho a la ciudad en Poble Sec, Barcelona, y defendida en enero de 2018, exploraba la práctica estética y pedagógica de dos colectivos surgidos en torno al Movimiento 15M: el Cinefòrum de la Assemblea de Veïns i Veïnes de Poble Sec (CPS) y el Taller de Ficció (TdF). Ambos empleaban la proyección de imágenes como una herramienta principal en sus actividades, y lo hacían asimismo mediante un dispositivo fluido y móvil (Castro-Varela, 2018b), que les permitía circular por diversos puntos de un mismo barrio. Miembro de los dos y cofundador además del segundo, el seguimiento etnográfico que llevé a cabo de sus respectivos devenires, entre 2012 y 2014, trató de esclarecer al ensamblaje de elementos humanos y no-humanos que sostenía su modo de existencia -calificado a partir de sus paradojas y tensiones como en común - y la política sociomaterial que le daba forma.

Las sesiones organizadas por el CPS, de enero y julio de 2012, y por el TdF, desde la primavera de 2012 hasta el otoño de 2014, buscaban en esencia producir un conocimiento colectivo en varios centros e instituciones públicas de Poble Sec. La proyección de una película de ficción o documental, en el primer caso, o de cortometrajes propios acerca de zonas del barrio urbanísticamente problemáticas, en el segundo, acostumbraba a alentar un debate en círculo que desgranaba o traducía a la situación actual las secuencias que acababan de verse. De esta forma, la esfera política vinculada al Movimiento 15M, la cual se había establecido en Poble Sec en julio de 2011 a través de una asamblea de vecinas, se conectaba con la vida cotidiana de su entorno y con otras personas y grupos no necesariamente afines en términos ideológicos. Mientras el relato de la Transición española, el significado de las huelgas generales, la noción de espacio público o la relación entre diseño arquitectónico y convivencia en una plaza del barrio, por poner varios ejemplos, se sometían a consideración a través del visionado de un filme, la estancia a oscuras - que podía ser en realidad un auditorio, una sala de reuniones o incluso una cocina- daba paso a una reconversión del público espectador en participantes de una especie de aula abierta. Esa práctica implicaba, evidentemente, la concurrencia y aleación de varios elementos espaciales, técnicos y corporales.

"Ensamblaje", a este respecto, es una noción a la que había accedido a través de la Actor-Network Theory (Callon, 1987; Latour, 2008). En contraposición a una "ciencia de lo social", la cual se remite siempre a "factores sociales" externos a los fenómenos que trata de explicar (Latour, 2008, pp.13-38), mi propósito consistió en rastrear las asociaciones que se daban de manera concreta en torno a la proyección audiovisual, tomando como centrales las incertidumbres y controversias que puntuaban su existencia. Esta fue grosso modo la agenda de cuestiones que la investigación trataba de desentrañar:

My ethnographic approach to both case studies aimed to explore in depth the entanglement that the film screenings gave rise to. This meant firstly recognizing which actors - human and non-human - took part in them, and what agency — understood as the power to create or modify a given situation — each actor had in 
running them. Other questions arose on the heels of this general one: how ideas and discourses were related to the construction and existence of the OPSC and FW, and to what extent what they did can also be understood as ideas and modes of being in themselves; how the screenings provoked disagreements or discussions about the relationships constituting the daily life of the neighbourhood, and what relational politics the screenings in turn involved; what kind of space-temporalities enabled the production of and were produced by the OPSC and FW activities; what divergences, approaches or openings took place between the case studies, the context of the Poble Sec people's assembly and the whole area; and lastly, what traces were left by the novelty of this aesthetic-cum-political assemblage. (Castro-Varela, 2018a, pp. 32-33).

\section{La cuestión de los afectos}

Sin embargo, al término de la escritura de la tesis empecé a valorar ciertas limitaciones que esta perspectiva ontoepistémico-metodológica comportaba. Una de ellas tenía que ver precisamente con el modo de existencia característico de las proyecciones que había relatado minuciosamente a lo largo de tres capítulos. En las sesiones del Cinefòrum o el Taller de Ficció, la manera en que se vinculaban el pase de películas y el debate colectivo al que daban lugar, los contenidos fílmicos y las problemáticas urbanas o políticas que se traducían de ellos, el equipo móvil y los lugares de proyección, los cuerpos y el mobiliario de cada sitio, y todo ello entre sí, no implicaban sólo una mera cuestión de conectividad, sino también de una cierta sensibilidad común a la hora de alcanzarla. Por ejemplo, la importancia de las prácticas de cuidado a fin de afrontar la precariedad del dispositivo técnico, de los horarios o de la mayoría de espacios de encuentro -cuyas condiciones distaban de la comodidad o la inmersión que suele ofrecer una sala de cine convencional- requerían que una fuerza compartida se movilizase de forma constante.

Ese despliegue "autopoiético" caracterizaba un modo de existencia extraño, en gran medida, al afán de la ANT por dar cuenta de la formación y funcionamiento de asociaciones más o menos estables. Las dimensiones afectiva y reproductiva que requiere su sostenibilidad (y especialmente la de ensamblajes o "agenciamientos" que, como en el caso del Cinefòrum y el Taller de Ficció, han de vérselas con una fragilidad perenne) no son tomadas en suficiente consideración por la perspectiva de Bruno Latour o Michel Callon. La vida en común que se daba en y en torno a la proyección de imágenes, en ambos casos de estudio, pasaba justamente por una tensión cotidiana entre fluidez y vulnerabilidad, apropiación espacial y mantenimiento, disposiciones colectivas y montajes que debían recomenzar casi en cada ocasión. Si los cuidados entendidos en un sentido amplio eran imprescindibles para sostener un tinglado sociomaterial con "pies de barro", ¿qué afectos sostenían a su vez ese anhelo compartido por reemprenderlos una y otra vez? ¿O debemos hablar esta vez, en lugar de sostenimiento, de correlación?

Lo cierto es que esa suerte de actualismo por parte de la ANT, que yo percibí al revisar la práctica de los casos de estudio, también es advertido por otras aproximaciones teóricas a la noción de ensamblaje:

Via the labour of tracing associations actor-network theory seeks to relate humans and non-humans in their co-production of the world, and in this work of relating the properties of parts - objects, artefacts, technical practices, humans, and so on - form logically necessary relations in the constitution of an actor-network. In DeLanda's vocabulary the actor-network becomes a 'seamless whole' that fully assimilates its component parts; nothing stands outside the descriptions that actor-network theory performs (Hetherington and Law, 2000: 128; Lee and Brown, 1994). The problem is that seeing entities as fully determined by their present relations makes it difficult to understand the efficacy of 'parts' by making the relational configuration into a homogeneous whole. (Anderson et al., 2012, p. 179).

Precisamente, la asociación de entidades que se producía en torno a las proyecciones del CPS y el TdF desafiaba la idea de un "todo sin costuras": la fragilidad de su orden hacía que debiera ser preservado continuamente a través de diversas prácticas de cuidado. De hecho, cabía entenderla más bien como una "coreografía ontológica" (Thompson, 2005) que emplea su coordinación dinámica para ejecutar una danza relacional y fílmica. ¿Era el deseo de estar en común, en y a 
pesar de dicha vulnerabilidad, el combustible que mantenía en marcha esa danza, o más bien su consecuencia, o acaso ambas cosas?

En las páginas previas al epílogo sí que había relatado en varias escenas las reacciones afectivas de los públicos durante las sesiones de cine. Se fundamentaba en la comprensión de Raymond Bellour (2013) sobre el espacio de proyección como un circuito hipnótico entre las espectadores y la película que transcurre en la pantalla. Bellour habla de un "entonamiento de afectos" que tiene lugar en la sala y que excede la mención de emociones discretas tales como rabia, felicidad, disgusto, temor, sorpresa, etc. Son en contraste los "afectos de vitalidad", que el psicólogo Daniel Stern (1985) opone a los "categoriales", los que según aquel movilizan el encuentro entre el cuerpo de los espectadores y el audiovisual del filme. Mientras que con los "afectos categoriales", "desde hace tanto tiempo y sobre todo desde Darwin, se ha querido dotar a las emociones de un sentido reconocible", los de "vitalidad" resultan "a la vez visibles y psicológicos y suponen la traducción expresiva de una sensación interior” (pp. 171-172). El propio Stern (1985, p. 80), citado por Bellour (ibid.), lo explica de la siguiente forma: "Hay mil sonrisas, mil conductas de levantarse-de- la-silla, mil variaciones en la ejecución de cualquiera y todos los comportamientos, y cada uno presenta un diferente afecto de vitalidad".

Ahora bien, esta tentativa no se extendió a los momentos que envolvían la proyección misma, como los preparativos de cada encuentro o la actividad dialógica, o simplemente festiva, que se añadía al pase del filme. Ese flujo transfílmico permaneció, por así decirlo, fuera de campo. Este texto apunta precisamente a afrontar, a partir de una teoría de los afectos de orientación feminista, esta carencia. Se trata en suma de interrogar las pasiones que constituyen y son constituidas por ensamblajes o agenciamientos en común.

\section{Transindividual sympathy}

Anna Hickey-Moody (2016) ha repensado "through a feminist lens" (p. 258) la noción de affectus que Gilles Deleuze (1990, 1998, 2003) toma de Spinoza, en aras de comprender mejor los intercambios materiales y posthumanos que se producen en torno a las prácticas artísticas. En la medida en que nos afectan y proporcionan nuevos modos de ver, sentir y relacionarnos con la realidad, el arte entraña siempre una orientació pedagógica. A su vez, añade Hickey-Moody, "this affective pedagogy of aesthetics is a spatial, temporal assemblage in which historicized practices of art production, ways of seeing, spaces and places of viewing are plugged into one another and augmented" (p. 259). Este marco de comprensión cuadra totalmente con la experiencia del CPS y el TdF, si bien no se limita al momento de las proyecciones, el cual devino sin duda central en el desarrollo de las sesiones, sino que también abarca la preparación de comida y bebida para antes o después del pase, las reuniones previas, la difusión del evento, la organización del espacio, el montaje del dispositivo, la distribución del mobiliario, las actividades corporales y dialógicas que sucedían a la película, y la recogida y limpieza. Llamaré pues "afectos transfílmicos" a las fuerzas que articulan ese hacer en común que no se circunscribe, sino que desborda e incluye, una sesión de cine destinada al aprendizaje colectivo.

En este sentido, Elizabeth de Freitas (2018) propone la noción de "transindividual sympathy" para comprender el caudal de afectos que atraviesan un ecología posthumana de aprendizaje, y que a la vez precede y transciende la existencia meramente individual de quienes la habitan. Consiste en un "sentir conjunto" que sostiene un proceso por el que se deviene otro sin borrar al otro. Según de Freitas, "one can identify three pivotal processes at work in sympathy —a contagion of feeling, a common sense or shared sensibility, and a compassion for the other entailing "response-ability", (p. 6). Mapear los momentos y rincones en que tales procesos estaban teniendo lugar, a contrapelo asimismo de modos de hacer más jerarquizados en cuanto al género o la división del trabajo, debería haber sido una tarea etnográfica fundamental para entender mejor la composición deseante de los ensamblajes del CPS y el TdF. También cómo se concretaba en ellos el clima afectivo que describo al principio de la tesis doctoral de la siguiente forma:

Como si la fraternidad, ese afecto que nos mantiene a la vista y nos aproxima cada semana en el barrio, a partir y después del 15M, tuviese por contraplano la persistencia de un cierto semianonimato (CastroVarela, 2018a, p. 49). 
O que una participante del Cinéforum, por su parte, explica también así: "De cop el barri era alegria i tendressa. Era trobar-nos a l'espai públic i pensar que som capaços de fer-ho tot. Ara volem un hort, un ateneu, una plaça, una festa major. Recordo com la sensació de que tot era posible" (Castro-Varela, 2018a, p. 128).

Ahora bien, el mapeo de esa "transindividual sympathy" requiere herramientas que, más allá de la observación participante y de una aproximación representacional, produzcan evidencias y rastros sobre los procesos mencionadosmás arriba. Si los acontecimientos son por definición aquello que se escapa a los marcos de reconocimiento preestablecidos, ¿cómo la metodología se convierte en una experimentación con lo real a través de la cual podemos desarrollar un seguimiento de los afectos y perceptos "in their twisting, braiding and knotting emergence" (De Freitas, 2018, p. 2)? En definitiva, esta tentativa de revisión de mi investigación doctoral acaba con una interrogación general: ¿cómo el mapa deviene el territorio de afectos que anhela (trans)figurar?

\section{Referencias}

Anderson, B., Kearnes, M., McFarlane, C. y Swanton, D. (2012). “On Assemblages and Geography” en Dialogues in Human Geography, 2 (2), pp. 171-189. London: Sage.

Bellour, R. (2013). El cuerpo del cine: hipnosis, emociones, animalidades. Santander: Shangrila Textos Aparte.

Callon, M. 1987. "Society in the Making: the Study of Technology as a Tool for Sociological Analysis" en. Bijker, W.E., Hughes, T.P y Pinch, T. (eds.), The Social Construction of Technological Systems: New Directions in the Sociology and History of Technology, pp. 83-103. Cambridge, Mass.: MIT Press.

Castro-V arela, A. (2018a). Estética de la proyección audiovisual. Asamblea, ficción y derecho a la ciudad en Poble Sec, Barcelona [Tesis doctoral]. Barcelona: Universitat de Barcelona. <http://hdl.handle.net/10803/461980> [Consulta: 10 de septiembre de 2019]

Castro-Varela, A. (2018b). “'Going Researcher' in the Occupy Poble Sec Cinema Forum: listening to the screenings and tracing a fluid assemblage of learning and care" en Ethnography and Education Journal, 13(3), pp. 396-412.

DE FreitAs, E. (2018). "The multidimensional mapping of transindividual sympathy" [Ponencia inaugural] en Cartographic approaches to teachers' corporeal, ecological and nomadic learning conference. Barcelona, 24 de octubre.

Deleuze, G. (1990). The Logic of Sense. New York: Colombia University Press.

Deleuze, G. (1998). Spinoza: Practical Philosophy. Minneapolis: City Light Books.

DeleuZe, G. (2003). Francis Bacon: The Logic of Sensation. Minneapolis: University of Minnesota Press.

Deleuze, G. y Guattari, F. (1987). A thousand plateaus. Minneapolis MN: University of Minnesota Press.

Hickey-Moody, A. (2016). "A Femifesta for Posthuman Art Education: Visions and Becomings" en Taylor, C. A. y Hughes, C. (eds.) Posthuman Research Practices in Education, pp. 258-266. UK: Springer.

LAtour, B. (2008). Reensamblar lo social. Una introducción a la teoría del actor-red. Buenos Aires: Manantial.

Massumi, B. (1987). “Translator's Foreword: Pleasures of Philosophy” en Deleuze G. y Guattari F. A Thousand Plateaus, pp. ix-xv. Minneapolis MN: University of Minnesota Press. 
Afectos transfilmicos: hacer y sentir en torno a la proyección audiovisual

STERN, D. 1985. The Interpersonal World of the Infant: a View from Psychoanalysis and Developmental Psychology. New York: Basic Books. 